\title{
DESENVOLVIMENTO DE MUDAS DE BRASSICA OLERACEA L. (BRÓCOLIS) EM DIFERENTES TIPOS DE SUBSTRATOS E BANDEJAS DE POLIESTIRENO.
}

Victoria Pontes Damasceno Araújo ${ }^{1}$, Luciano Gomes Ferreira ${ }^{2}$, Michel Velter Maggioni ${ }^{3}$, Priscila Raisa Moura de Mattos $^{4}$, Rafael Vinícius de Arruda ${ }^{5}$

1 Graduada em Agronomia pela Unic- Universidade de Cuiabá-MT

(victoria_pontes_araujo@hotmail.com)

2 Engenheiro Agrônomo M. Sc., Professor do Curso de Agronomia do Centro

Universitário de Várzea Grande-MT(UNIVAG) e doutorando em Agricultura

Tropical/UFMT

3 e 4 Graduandos em Agronomia pela Univag - Centro Universitário de Várzea Grande-MT

5 Graduado em Agronomia pela Unic- Universidade de Cuiabá-MT

Recebido em: 06/04/2019 - Aprovado em: 10/06/2019 - Publicado em: 30/06/2019 DOI: 10.18677/EnciBio_2019A341

\section{RESUMO}

A utilização de bandejas de isopor para a produção de mudas tem se mostrado um sistema eficiente sob diversos aspectos, como economia de substrato e de espaço dentro da casa de vegetação e produção de mudas de alta qualidade. Avaliou-se o desenvolvimento de mudas de Brócolis Brassica oleracea L. var. italica (Brócolis), cv. Piracicaba, produzidas em diferentes tipos de bandejas de poliestireno (isopor) e de substratos na casa de vegetação do campo experimental do UNIVAG - Centro Universitário de Várzea Grande no período de 3 de junho a 3 de julho de 2017. O delineamento experimental utilizado foi o de blocos ao acaso em esquema fatorial 3 x 5, compreendendo três tipos de bandejas de poliestireno (128; 200 e 288) células, cinco tipos de substratos (VivattoPlus ${ }^{\circledR}$, Terra Nova ${ }^{\circledR}$, Carolina Soil®, Tecnomax®, Vitaplan( $\left.{ }^{(}\right)$, com duas repetições. Foram avaliadas as seguintes características: largura da folha (LF), comprimento da folha (CF), comprimento de raiz (CR) e massa seca da parte aérea (MSPA). Constatou-se que o substrato comercial Carolina Soil resultou no melhor desenvolvimento das mudas, a bandeja de 128 células apresentou melhor desenvolvimento agronômico para as variáveis analisadas.

PALAVRAS-CHAVE: Brassica oleracea I., Hortaliças, Piracicaba, Propagação.

\section{DEVELOPMENT OF SLEENDLING IN BRASSICA OLERACEA L.(BROCCOLI) DIFFERENT TYPES OF SUBSTRATES AND POLYSTYRENE TRAYS.}

\begin{abstract}
The use of styrofoam trays for the production of seedlings has shown to be an efficient system in several aspects, such as substrate and space saving inside the greenhouse, and high seedling production quality. The development of Brócolis Brassica oleracea L (Broccolis) cv. Piracicaba produced in different types of polystyrene trays and of substrates the greenhouse of the experimental field of
\end{abstract}


UNIVAG - University Center of Várzea Grande from June 3 to July 3, 2017. The experimental design used was that of blocks in a $3 \times 5$ factorial scheme comprising three types of polystyrene trays $(128,200$ and 288) cells, five types of substrates (VivattoPlus $\AA$, Terra Nova $\AA$, Carolina Soil®, Tecnomax®, Vitaplan $\AA$ ) with two replicates. The following characteristics were evaluated: leaf width (LF), leaf length (CF), root length (CR), dry shoot mass (MSPA). It was observed that, regardless of the type of substrate, the tray of 128 cells presented better agronomic development for the variables analyzed.

KEYWORDS: Brassica oleracea I., Vegetables, Piracicaba, Propagation.

\section{INTRODUÇÃO}

Dentre as hortaliças de importância econômica no Brasil, o Brócolis (Brassica oleracea L.) pertencente família das Brassicaceae, é uma das hortaliças com introdução mais recente no Brasil e seu cultivo vem aumentando gradativamente nas últimas décadas (SCHIAVON , 2015).

Originário da Europa e possivelmente também da Ásia Ocidental, sendo conhecido também como brócolos. É uma variedade botânica da mesma espécie que a couve primitiva e morfologicamente semelhante à couve-flor, especialmente na fase vegetativa e, na fase reprodutiva apresenta uma inflorescência central, compacta (tipo "cabeça") de coloração verde-escura, formada por pequenos botões florais ainda fechados e pedúnculos tenros. Entre todas as Brassicaceae, o brócolis se destaca por ser uma das mais ricas em proteínas, cálcio e pró-vitamina A (betacaroteno) e vitamina $C$ que se perde, em parte, durante o cozimento (DA SILVA, 2014).

Entre os dois últimos censos agropecuários realizados em 1995 e 2006, considerando as 57 espécies levantadas, a produção de brócolis aumentou em $152 \%$, passando da vigésima sétima para a vigésima hortaliça mais produzida no Brasil, com 91.653 toneladas. (IBGE, 2011).

Segundo a Companhia de Entrepostos e Armazéns Gerais de São Paulo (CEAGESP), em 2013 a quantidade comercializada de brócolis ramoso no Estado de São Paulo foi de $7.704 .480 \mathrm{~kg}$. Devido ao aumento do consumo dessa hortaliça, tornou-se grande vantagem pela demanda no mercado e riqueza nutricional. (SANTANA, 2015).

Em Mato Grosso, estudos sobre o cultivo do Brócolis ainda são incipientes desde a etapa da produção das mudas como o cultivo a campo. A produção de mudas é uma das etapas mais importantes do processo produtivo. Para se produzir mudas de qualidade, dois fatores fundamentais são a utilização de recipientes e substratos adequados. O primeiro tem influência direta no volume disponível para o desenvolvimento das raízes e o segundo, exerce uma importância marcante na arquitetura do sistema radicular e no estado nutricional das plantas, afetando profundamente a qualidade das mudas (MOTTA et al., 2018). Para isso, a escolha do substrato é de fundamental importância, pois é determinante para o crescimento e vigor vegetativo da muda até o momento de seu plantio no campo (SILVA, 2010).

A utilização de bandejas de isopor para a produção de mudas tem apresentado um sistema eficiente. Esse sistema proporciona maior cuidado na fase de germinação e emergência, fazendo com que, muitas vezes, uma semente origine uma planta, além de proporcionar menor custo no controle de pragas e doenças, alto 
índice de pegamento após o transplante e, ainda é possível a reutilização do mesmo.As plântulas devem encontrar condições satisfatórias para o processo de germinação de sementes e seu desenvolvimento, mesmo havendo restrições de espaços das células nas bandejas(SILVA, 2010).

No Brasil, os substratos agrícolas são feitos a partir de materiais de origem natural como: turfas, compostos orgânicos, vermiculita expandida, casca de arroz carbonizada, fibra de coco, casca de pinus compostada, serragem, bagaço de cana, moinha ou fino de carvão e capins compostados, entre outros (FERMINO, 2014).

Os substratos devem ser mais eficientes que os solos em características como permeabilidade, poder de tamponamento para valor de $\mathrm{pH}$ e capacidade de retenção de nutrientes e água (MOTTA et al., 2018). Cada tipo de substrato possui naturezas físicas e químicas diferentes uns dos outros., no entanto, existem problemas de como assegurar o crescimento e produção de biomassa aérea com volume limitado de solo, o tamanho do recipiente e o tipo do substrato. Tais características são consideradas as primeiras particularidades a serem investigadas para que seja garantida a qualidade das mudas.

Atualmente existe uma diversidade de opções de diferentes tipos de substratos e bandejas disponíveis no mercado que exige a realização de trabalhos científicos que possam subsidiar a decisão dos produtores quanto à escolha do melhor tipo de substrato e bandeja, visando obter mudas de qualidade e evitar o desperdício de insumos. A pesquisa em tela teve como objetivo verificar o desenvolvimento agronômico de mudas de Brócolis da cultivar Piracicaba, sob efeito de diferentes tipos de bandejas de poliestireno e tipos de substrato nas condições do município de Várzea Grande Mato Grosso.

\section{MATERIAL E MÉTODOS}

O experimento foi desenvolvido em casa de vegetação na área experimental do Centro Universitário de Várzea Grande - UNIVAG, localizado no município de Várzea Grande - MT nas coordenadas de Latitude "15³3'39" S, Longitude “56 $05^{\circ} 53^{\prime}$ " W, com altitude em torno de $183 \mathrm{~m}$, no período entre 3 de junho a 3 de julho de 2017.

O delineamento utilizado foi de blocos ao acaso em esquema fatorial $3 \times 5$, compreendendo três tipos de bandejas de poliestireno (128; 200 e 288) células, cinco tipos de substratos (Vivatto Plus $\AA$, Terra Nova $\AA$, Carolina Soil $®$, Tecnomax $\AA$, Vitaplan( $\left.{ }^{(}\right)$em duas repetições, totalizando 30 parcelas com 16 plantas cada. Os tratamentos resultaram da combinação de três recipientes com diferentes volumes, sendo este recipiente, bandejas de poliestireno (isopor). (Tabela 1).

TABELA 1. Bandejas de poliestireno (isopor) utilizadas na produção de mudas de Brócolis. Várzea Grande-MT, 2017.

\begin{tabular}{cccc}
\hline Tipos de Bandeja & 1 & 2 & 3 \\
\hline $\begin{array}{c}\text { Quantidade de } \\
\text { células }\end{array}$ & 128 & 200 & 288 \\
\hline Volume de Substrato & $34,6 \mathrm{~cm}^{3}$ & $16 \mathrm{~cm}^{3}$ & $12 \mathrm{~cm}^{3}$ \\
\hline
\end{tabular}


Os substratos utilizados foram adquiridos junto ao comércio local, em lojas especializadas em produtos agropecuários e sua composição, conforme quadro 1.

QUADRO 1. Substratos comerciais utilizados na produção de mudas de Brócolis. Várzea Grande-MT, 2017.

\begin{tabular}{|l|l|l|}
\hline Substrato & Nome Comercial & Composição \\
\hline 1 & Vivatto Plus $\AA$ & $\begin{array}{l}\text { Casca de pinus, bio-estabilizada, vermiculita, } \\
\text { moinha de carvão vegetal, água e espuma } \\
\text { fenólica. }\end{array}$ \\
\hline 2 & Terra Nova® & $\begin{array}{l}\text { Húmus, cinza, fibras vegetais, arenito moído, } \\
\text { calcário, pó e cascas de pinus decomposto. }\end{array}$ \\
\hline 3 & Carolina Soil® & $\begin{array}{l}\text { Turfa de sphagno,vermiculita expandida, } \\
\text { calcário, NPK. }\end{array}$ \\
\hline 5 & Tecnomax® & $\begin{array}{l}\text { Vermiculita expandida, casca de pinus, cinza, } \\
\text { fibra de coco e carvão vegetal. }\end{array}$ \\
\hline 5 & Vitaplan® & $\begin{array}{l}\text { Casca de pinus, composto orgânico, areia para } \\
\text { substrato e esterco de galinha. }\end{array}$ \\
\hline
\end{tabular}

A análise da composição química dos substratos foi realizada a partir de amostras individuais de cada substrato contendo 500 gramas, e encaminhadas para analise em laboratório de acordo com os resultados demonstrados, conforme (Tabela 2).

TABELA 2. Caracterização química de diferentes substratos utilizados na produção de mudas de Brócolis, Várzea Grande-MT 2017.

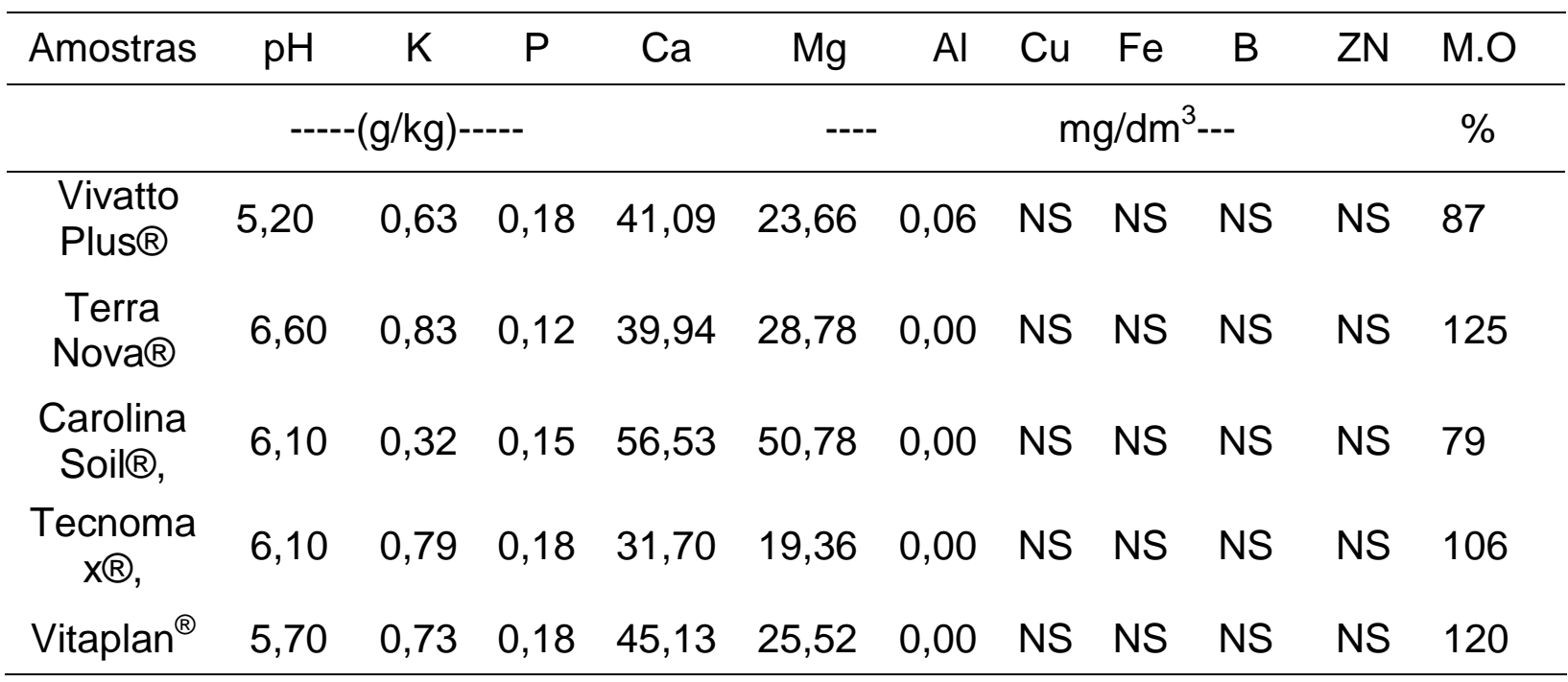

Para a produção das mudas foram usadas sementes de Couve Couve Brócolis Piracicaba Precoce (Brassica oleracea L. var. itálica) resistente a temperaturas elevadas (FERREIRA et al., 2013). Antes da semeadura realizou-se a lavagem e a desinfecção das bandejas, emergindo-as em solução contendo $2 \%$ de 
hipoclorito de sódio (água sanitária) por aproximadamente um minuto, para promover assepsia do material de produção de mudas (OLIVEIRA, 2016).

Momentos antes de realizar a semeadura, realizou-se o molhamento dos substratos com o intuito de obter uma mesma umidade e padronizar a germinação das sementes. Posteriormente, molhou-se também as bandejas para que quando fossem colocados os substratos, houvessem uma melhor aderência e permanência dos mesmos nas células (CRIPPA;FERREIRA 2015). Em seguida procedeu-se a semeadura, onde foram semeadas duas sementes por célula.

A realização da semeadura foi no dia 3 de Junho de 2017, sendo semeadas duas sementes no centro de cada célula. Seguidamente as bandejas foram levadas para uma casa de vegetação protegida com sombrite a $50 \%$ de sombreamento, onde permaneceram suspensas do chão e irrigadas diariamente, uma vez ao dia no período matutino, com o auxílio de um regador de 5 litros, evitando que a água escorresse das células e reduzindo a lixiviação de nutrientes. As plantas emergiram no terceiro dia após a semeadura, em todas as bandejas.

Para evitar problemas de germinação, a realização do desbaste de mudas 10 dias após a semeadura foi fundamental evitando assim, o adensamento e a ocorrência de competição por nutrientes, devido à grande quantidade de mudas, deixando apenas uma por célula (OLIVEIRA, 2014). A produção de mudas em casa de vegetação é bastante vantajosa, pois conta com um melhor controle de pragas e doenças (ARAUJO et al., 2016). Com isso, não foi necessário nenhum tipo de controle fitossanitário durante o desenvolvimento das mudas.

As avaliações foram realizadas aos 31 dias após a semeadura, período em que as mudas apresentavam crescimento vigoroso e o surgimento de quatro a seis folhas definitivas. Neste momento, foram coletadas oito plantas da área útil de cada parcela para determinar o melhor desenvolvimento entre os substratos e as bandejas, avaliando-se as seguintes características: Largura da Folha (LF); comprimento da folha (CF); comprimento de raiz (CR); massa seca da parte aérea (MSPA) e massa seca da raiz (MSR).

Para determinação das medições foi utilizado um paquímetro analógico onde se obteve as unidades de medidas em milímetros $(\mathrm{mm})$ medindo 0 comprimento das folhas a partir do limbo foliar, a largura a partir das laterais da folha e o comprimento das raízes medido a partir do coleto das mudas. Foram medidas cada característica em oito plantas de cada parcela, cujas médias foram submetidas a uma análise estatística.

Para a determinação do MSPA foi utilizada uma estufa do Laboratório de Sementes do UNIVAG. As amostras foram separadas e colocadas na estufa contendo a parte aérea e a raiz de oito plantas de cada parcela em saco de papel Kraft. Posteriormente, foi utilizada estufa de circulação forçada para secagem do material. As mesmas permaneceram na estufa por 72 horas em uma temperatura de $60^{\circ} \mathrm{C}$. Depois da secagem no tempo determinado, as amostras foram pesadas utilizando-se a balança analítica da marca GEHAKA, modelo AG $200 \mathrm{com}$ precisão de $+0,0001$ grama e capacidade para $210 \mathrm{~g}$, onde se procederam a pesagem do material na mesma unidade.

Os dados obtidos foram submetidos à análise de variância e comparação entre as médias, sendo feitas pelo teste de Tukey a $5 \%$ de probabilidade, utilizando-se o programa estatístico Assistat Software (SILVA, 2016). 


\section{RESULTADOS E DISCUSSÕES}

Observou- se que para a variável Área foliar (AF), a interação entre os fatores bandeja e substrato demonstra que para a bandeja de 128 células não houve diferença significativa entre os substratos. Entretanto, para a bandeja de 200 células os melhores resultados foram Vivatto Plus ${ }^{\circledR}$, Terra Nova ${ }^{\circledR}$, e Vitaplan ${ }^{\circledR}$ e para 288 células, a Terra Nova foi a melhor.

A bandeja de 128 células caracterizou-se como melhor recipiente, por causa do volume de acondicionamento de substrato ser maior em comparação as bandejas de 200 e 288 células, assim podendo a cultura ter um melhor desenvolvimento das raízes, bem como da área foliar, proporcionando melhor quantidade de nutrientes disponível para a futura planta.

Em distintos trabalhos realizados com outras hortaliças como, Melancia (SILVA, 2016); Couve flor (BEBER, 2014); e Repolho (CRIPPA;FERREIRA 2013); os resultados confirmaram que a bandeja de 128 células promoveu o melhor desenvolvimento nas variáveis LF, CF, CR, sendo esta bandeja mais propícia à obtenção de mudas altamente desenvolvidas e sadias.

Segundo Crippa e Ferreira (2015) foram observadas características significativas no desenvolvimento das raízes entre as bandejas e substratos, tendo que as bandejas de 128 células tiveram valores maiores para as características MSPA, CF, LF e CR em comparação a bandejas de 200 e 288 células.

TABELA 3. Área Foliar (AF), comprimento da folha (cm) de mudas de Brócolis produzidas em cinco substratos e três diferentes tipos de bandeja. UNIVAG, Várzea Grande - MT.2017.

\begin{tabular}{lllllll}
\hline \multirow{2}{*}{ Bandeja } & \multicolumn{5}{c}{ Substrato } \\
\cline { 2 - 6 } & Vivatto & $\begin{array}{l}\text { Terra } \\
\text { Nova }\end{array}$ & $\begin{array}{l}\text { Carolina } \\
\text { Soil }\end{array}$ & $\begin{array}{l}\text { Tecnoma } \\
\mathbf{x}\end{array}$ & Vitaplan & Média \\
200 & $2,55 \mathrm{aB}$ & $2,43 \mathrm{aB}$ & $3,25 \mathrm{aA}$ & $2,78 \mathrm{Ab}$ & $2,54 \mathrm{aB}$ & $2,71 \mathrm{a}$ \\
288 & $2,38 \mathrm{aA}$ & $2,38 \mathrm{aA}$ & $2,61 \mathrm{bA}$ & $2,26 \mathrm{bA}$ & $2,42 \mathrm{aA}$ & $2,41 \mathrm{~b}$ \\
\cline { 2 - 6 } & $1,68 \mathrm{bB}$ & $2,17 \mathrm{aA}$ & $2,31 \mathrm{bA}$ & $1,95 \mathrm{bAB}$ & $2,00 \mathrm{aB}$ & $2,02 \mathrm{C}$ \\
\hline Média & $2,02 \mathrm{~B}$ & $2,33 \mathrm{~B}$ & $2,72 \mathrm{~A}$ & $2,33 \mathrm{~B}$ & $2,32 \mathrm{~B}$ & \\
\hline CV (\%) & $\mathbf{5 , 6 0}$ & & & & &
\end{tabular}

Médias seguidas de mesma letra minúsculas na coluna e maiúscula na linha, não diferem entre si, a $5 \%$ de probabilidade, pelo teste de Tukey.

Para a variável $C R$ não houve diferença significativa entre os substratos testados na bandeja de 128 células. Entretanto para bandeja de 200 células os melhores resultados foram Vivatto, Terra Nova, Tecnomax e Vitaplan e para 288 Vitaplan. Na mesma variável a bandeja de 128 células e o substrato Carolina Soil apresentaram melhores resultados, devido a essa combinação de promover um ambiente que possibilitou a realização de fotossíntese e crescimento da muda com maior espaço. Em relação aos diferentes tipos de substrato, para o CR houve diferença significativa no desenvolvimento das mudas utilizando o Carolina Soil, onde as médias foram melhores. (Tabela 4) 
TABELA 4. Comprimento da raiz (CR) de mudas de Brócolis produzidas em cinco substratos e três diferentes tipos de bandejas. UNIVAG, Várzea Grande - MT.2017.

\begin{tabular}{lllllll}
\hline \multirow{2}{*}{ Bandeja } & \multicolumn{5}{c}{ Substrato } \\
\cline { 2 - 6 } 128 & Vivatto & $\begin{array}{l}\text { Terra } \\
\text { Nova }\end{array}$ & $\begin{array}{l}\text { Carolina } \\
\text { Soil }\end{array}$ & Tecnomax & Vitaplan & Média \\
\cline { 2 - 6 } 200 & $4,87 \mathrm{aB}$ & $5,09 \mathrm{aAB}$ & $5,66 \mathrm{aA}$ & $5,13 \mathrm{aAB}$ & $4,07 \mathrm{aC}$ & $4,96 \mathrm{a}$ \\
288 & $4,62 \mathrm{aA}$ & $4,85 \mathrm{aA}$ & $4,92 \mathrm{bA}$ & $4,70 \mathrm{aA}$ & $3,96 \mathrm{aB}$ & $4,61 \mathrm{~b}$ \\
& $3,48 \mathrm{bB}$ & $3,98 \mathrm{bAB}$ & $4,40 \mathrm{bA}$ & $3,83 \mathrm{bAB}$ & $3,77 \mathrm{aB}$ & $3,89 \mathrm{C}$ \\
\hline Média & $4,32 \mathrm{~B}$ & $4,64 \mathrm{AB}$ & $4,99 \mathrm{~A}$ & $4,55 \mathrm{~B}$ & $3,93 \mathrm{C}$ & \\
\hline CV (\%) & $\mathbf{4 , 5 3}$ & & & & & \\
\hline
\end{tabular}

Médias seguidas de mesma letra minúsculas na coluna e maiúscula na linha, não diferem entre si, a $5 \%$ de probabilidade, pelo teste de Tukey.

Para a variável $L F$, a interação entre os fatores bandeja e substrato demonstram que para a bandeja de 128 células houve diferença significativa entre os substratos, destacando Carolina Soil havendo melhor desempenho. Entretanto, para a bandeja de 200 células tiveram melhor desempenho na largura de folha os substratos Vivatto ${ }^{\circledR}$, Terra Nova $^{\circledR}$ e Tecnomax ${ }^{\circledR}$.

Os substratos Carolina Soil ${ }^{\circledR}$ e Vivatto mostraram maior eficiência em largura de folha nas bandejas de 200 células, onde também Carolina Soil ${ }^{\circledR}$ e Vitaplan ${ }^{\circledR}$ obtiveram significância na LF em bandejas de 288 células. Em relação aos diferentes tipos de substrato para a mesma varável, houve diferença significativa no desenvolvimento das mudas utilizando o Carolina Soil ${ }^{\circledR}$ onde foram obtidas as melhores médias. (Tabela 5).

TABELA 5. Largura da folha (LF) de mudas de Brócolis produzidas em cinco substratos e três diferentes tipos de bandejas. UNIVAG, Várzea Grande - MT. 2017.

\begin{tabular}{lllllll}
\hline \multirow{2}{*}{ Bandeja } & \multicolumn{5}{c}{ Substratos } \\
\cline { 2 - 6 } 128 & Vivatto & $\begin{array}{l}\text { Terra } \\
\text { Nova }\end{array}$ & $\begin{array}{l}\text { Carolina } \\
\text { Soil }\end{array}$ & Tecnomax & Vitaplan & Média \\
\cline { 2 - 6 } 200 & $2,93 \mathrm{aBC}$ & $2,65 \mathrm{aC}$ & $3,59 \mathrm{aA}$ & $3,20 \mathrm{aB}$ & $2,74 \mathrm{aC}$ & $3,02 \mathrm{a}$ \\
288 & $2,84 \mathrm{aA}$ & $2,39 \mathrm{bB}$ & $2,87 \mathrm{bA}$ & $2,50 \mathrm{bB}$ & $2,52 \mathrm{abB}$ & $2,62 \mathrm{~b}$ \\
\hline Média & $2,04 \mathrm{bC}$ & $2,30 \mathrm{bB}$ & $2,63 \mathrm{bA}$ & $2,21 \mathrm{cBC}$ & $2,48 \mathrm{bAB}$ & $2,33 \mathrm{c}$ \\
\hline $\mathbf{C V}(\%)$ & $\mathbf{3 , 5 6}$ & $2,44 \mathrm{c}$ & $3,03 \mathrm{a}$ & $2,63 \mathrm{~b}$ & $2,58 \mathrm{bc}$ & \\
\hline
\end{tabular}

Médias seguidas de mesma letra minúsculas na coluna e maiúscula na linha, não diferem entre si, a $5 \%$ de probabilidade, pelo teste de Tukey. 
Com relação aos resultados para MSPA, observou-se que houve diferença significativa quanto ao comportamento em bandeja (Tabela 7). Na mesma variável, o melhor resultado foi obtido em bandeja de 128 células em comparação com as demais.

A bandeja de 128 células caracterizou-se como melhor recipiente, em função do volume de acondicionamento de substrato ser maior em comparação às bandejas de 200 e 288 células, podendo, assim, favorecer o desenvolvimento radicular da cultura, mostrando significância na interação dos fatores analisados, fornecendo maior quantidade de nutrientes

TABELA 6. Matéria Seca parte aérea (MSPA) de mudas de Brócolis da cultivar Piracicaba, em função do tipo de bandeja (128, 200, 288 células), UNIVAG, Várzea Grande - MT.2017.

\begin{tabular}{ll}
\hline Bandejas & Aérea \\
\hline Quantidade de células & $-----g$ \\
\hline 128 & $0,063 \mathrm{a}$ \\
\hline 200 & $0,523 \mathrm{~b}$ \\
\hline 288 & $0,028 \mathrm{~b}$ \\
\hline CV\% & $\mathbf{2 0 , 9 3}$ \\
\hline
\end{tabular}

Médias seguidas pela mesma letra não diferem entre si estatisticamente pelo teste de Tukey a $5 \%$ de probabilidade.

Ainda para a variável MSPA, o melhor resultado foi obtido com o substrato Carolina Soil ${ }^{\circledR}$ em comparação com os demais. Tal variável se mostrou estatisticamente superior no substrato Carolina Soil ${ }^{\circledR}$ e nas bandejas de 128 células, devido a essa combinação entre recipiente com maior volume e substrato, que ofereceu melhores nutrientes para que as raízes primárias pudessem desenvolver raízes secundaria e terciarias em maior quantidade que os outros recipientes e substratos.

TABELA 7. Matéria seca da parte aérea (MSPA) de mudas de Brócolis da cultivar Piracicaba, em função do tipo de substrato. UNIVAG, Várzea Grande - MT. 2017.

\begin{tabular}{cc}
\hline Substratos & Aérea \\
\hline & $-----\mathrm{g}----$ \\
\hline Vivatto & $0,049 \mathrm{ab}$ \\
\hline Terra Nova & $0,037 \mathrm{~b}$ \\
\hline Carolina Soil & $0,064 \mathrm{a}$ \\
\hline Tecnomax & $0,046 \mathrm{ab}$ \\
\hline Vitaplan & $0,042 \mathrm{~b}$ \\
\hline CV\% & $\mathbf{2 0 , 9 3}$
\end{tabular}

Médias seguidas pela mesma letra não diferem entre si estatisticamente pelo teste de Tukey a $5 \%$ de probabilidade. 
Com relação ao fator substrato, dentre todas as variáveis analisadas, o Carolina Soil ${ }^{\circledR}$ destacou-se nas variáveis AF, LF, CR. Quanto aos demais substratos estudados para as mudas de Brócolis, cultivar Piracicaba, o Vitaplan ${ }^{\circledR}$, o Vivatto ${ }^{\circledR}$, o Plus e o Terra Nova ${ }^{\circledR}$ apresentaram as menores medias. As variáveis destacadas (AF, LF e CR), demonstraram que o manejo na formação de mudas e a escolha do substrato ideal são determinantes para produzir mudas de brócolis com qualidade e bom desenvolvimento.

Segundo Coelho et al., (2013) a produção de mudas garante um ótimo retorno econômico para o produtor, pois ele terá muito mais segurança produtiva e menor custo na implantação. Atualmente, a utilização de bandejas de plástico com substrato comercial é o método mais utilizado para produzir mudas de hortaliças.

Com relação aos desenvolvimentos da interação Recipiente x Substrato, feito para as variáveis LF, CF e CR, ocorreram que as bandejas de 128 células favorecem melhor desenvolvimento das mudas independente da composição do substrato utilizado. Esse resultado se deve ao volume de substrato retido por célula ao qual promoveu melhor desenvolvimento.

Quanto aos substratos utilizados, o Carolina Soil® destacou-se na maioria das variáveis analisadas para o cultivo de mudas de Brócolis. Isto pode ser explicado porque o mesmo apresentou melhor teor de cálcio, auxiliando no desenvolvimento radicular. O desempenho do substrato Carolina soil ${ }^{\circledR}$ em seu estudo de desempenho na produção de mudas de brócolis com substratos alternativos obteve melhores resultados e viabilidade em sua utilização (MOTTA et al., 2018).

Existem diversos tipos e tamanhos de bandejas para produção de mudas, e a tendência é a utilização de bandejas que possuem número reduzido de células e maior número de substrato (MOREIRA et al., 2018). Segundo Godoy e Cardoso (2005) a interação entre o volume de célula e a idade de transplantio para a maior parte das características, o maior desenvolvimento das mudas produzidas nas bandejas de 128 células é um indicador de desenvolvimento da planta que é influenciado pela quantidade de substrato disponível.

\section{CONCLUSÃO}

O substrato Carolina Soilß apresentou melhor capacidade na produção de mudas da cultivar Piracicaba e demais características, com melhor desenvolvimento em área foliar, comprimento de folhas e de raízes.

Independente do substrato, a bandeja de 128 células proporcionou melhor desenvolvimento agronômico de mudas.

\section{REFERÊNCIAS}

ARAúJO , A. M. C. D., CATAPAN, A. H., KASSICK, C. N., \& LAFFIN, M. (2016). Currículo Referência-Eixo Tecnológico Recursos Naturais (RNT) - Técnico em Agropecuária.

BEBER, N. V. C. Desenvolvimento de mudas de couve-flor var. piracicaba precoce sob efeitos de diferentes tipos de bandejas e substratos. Tcc Publicado no Centro Universitário de Várzea Grande-MT; 2014, p.: 1/13

CRIPPA, J. P. B.; FERREIRA, L. G. Desenvolvimento de mudas de repolho em diferentes tipos de bandeja e substrato. CONNECTION LINE, n. 12, 2015. 
Disponível

em:

<http://periodicos.univag.com.br/index.php/CONNECTIONLINE/article/view/209>.

Doi: 10.18312

COELHO, J.L.S.;SILVA, R.M.; BAIMA, W.D.S.; GONSALVES, H.R.O.; SANTOS NETO, F.C.; et al., Diferentes substratos na produção de mudas de pimentão. Agropecuária Científica no semiárido, v. 9, n. 2, p. 01-04, 2013. Disponível em: < http://revistas.ufcg.edu.br/acsa/index.php/ACSA/article/view/343>.

Doi: 10.30969/acsa.v9i2.343

DA SILVA, P. A.; Produção de brócolis fertirrigado com nitrogênio em dourados, ms. 2014.

FERREIRA, S.; De SOUZA, R. J.; Gomes, L. A. A. Produtividade de brócolis de verão com diferentes doses de bokashi. Revista Agrogeoambiental, v. 5, n. 2, 2013.

FERMINO, M. H. Substratos: composição, caracterização e métodos de análise.

Guaíba: Agrolivros, 2014. 112 p.

GODOY, M. C.; Cardoso, A. I. I. Produtividade da couve-flor em função da idade de transplantio das mudas e tamanhos de células na bandeja. Horticultura Brasileira, p. 837-840, 2005.

IBGE -Instituto Brasileiro de Geografia e Estatística . Sistema IBGE de Recuperação Automática - SIDRA. Brasília: IBGE, 2011. Disponível em:<http://www.sidra.ibge.gov.br/bda/tabelaprotabl.asp?c=818\&z=t\&o=1\&i=P>. Acesso em: 28 junho 2017.

MOTTA, I.; COMUNELLO, E.; Da SILVA, S.; L.; PADOVAN, M. P.; \& MARTINS, P. O. (2018). Mudas de brócolis de cabeça sob a influência de quatro recipientes e três substratos. Cadernos de Agroecologia, 13(2), 8-8. Seminário de sistemas agroflorestais em bases agroecológicas de MATO GROSSO DO SUL, 3., 2018, Campo Grande, MS. Sistemas agroflorestais agroalimentares, sociobiodiversidade, saúde, educação: desafios e perspectivas. Campo Grande, MS, 2018. AGROECOL 2018, 2018.

MOREIRA, L. A. M.; De OLIVEIRA, M. D. R.; FERREIRA, L. G. Desenvolvimento de mudas de melão sob efeitos de diferentes tipos de bandejas e substratos. Caderno de Publicações Univag, n. 08, 2018.

Disponivel em: <https://www.periodicos.univag.com.br/index.php/caderno/article/view/794/956>.

DOI:10.18312

OLIVEIRA, F. A.; Rendimento do maxixeiro cultivado em substrato e fertirrigado com diferentes soluções nutritivas. Horticultura Brasileira, v. 32, n. 04, 2014. 
OLIVEIRA, M. C.; Manual de viveiro e produção de mudas: espécies arbóreas nativas do Cerrado. Embrapa Cerrados-Outras publicações científicas (ALICE), 2016.

SANTANA, F. M. S.; Aplicação de produtos de efeitos fisiológicos na pro-dução de brócolis tipo ramoso. 2015.

SCHIAVON, A. A cultura dos brócolis. Brasília. Embrapa -SPI/ Embrapa-CPAMN, 2015. 9 p. (Coleção Plantar).

SILVA, J. C. Mudas de cafeeiro (Coffeaarabica L.) desenvolvidas sob fontes de material orgânico no substrato comercial. 2010. 48 f. Dissertação (Mestrado em Agronomia) - Universidade Federal de Uberlândia (UFU), Uberlândia. 2010.

SILVA, C. C.; Avaliação de diferentes tipos de substratos na produção de mudas de melancia.2016. Disponivel em: < http://hdl.handle.net/123456789/1394>. 